\title{
Regulatory and legal means of ensuring food security and its role in the implementation of national priorities of the Russian Federation
}

\author{
Nikolay Sarayev ${ }^{1, *}$ and Svetlana Studenikina ${ }^{1}$ \\ ${ }^{1}$ Don State Technical University, 344003, pl. Gagarina, 1, Rostov-on-Don, Russia
}

\begin{abstract}
The purpose of this work is to establish and determine, on the basis of a systematic analysis, the factors influencing the state of food security of the Russian Federation, the problems of legal support of national priorities related to food independence. Qualitative and quantitative characteristics of the current state of food security in the Russian Federation are closely related to the criteria for the development of the socio-economic system of the state. An important condition for the effective implementation of national priorities is the normative regulation of the toolkit of state management impact on the threats and risks of food independence. To understand the essence of these problems and minimize their consequences, the authors substantiate the need to study the indicated problem within the framework of the concept of legal dementia. Legal dementia is a state of compliance by subjects of law with the provisions of the law, which is characterized by non-fulfillment to one degree or another by state bodies not only of their functions, but also by the inability to respond, due to a low level of competence and professionalism, to factors that weaken the effectiveness of legal guarantees.
\end{abstract}

\section{Introduction}

In the context of a significant impact on the current state of public relations in the Russian Federation, the processes of globalization, the consequences of an unfavorable epidemiological situation and sanctions pressure, the issues of ensuring national priorities become especially acute and require scientific understanding and urgent adoption of a set of measures with a solid foundation for their legal support.

Among the fundamental qualitative characteristics of the socio-economic system of any state at any stage of its historical development is the food component, which is designed not only to meet the needs of the population for food, but is also an element of maintaining the health of the nation, a generator of the energy potential of industrial activity.

At the same time, studies show that the lack of a timely legal response to containment of risk factors contributes to the growth of vulnerability not only to food security, but also to

\footnotetext{
*Correcting author: snv_571978@mail.ru
} 
national security in general. This is due to the fact that the institutional structure of food security is a complex multifunctional mechanism that covers political, social, economic, demographic, environmental and other aspects of public life. Effective legal regulation of food safety elements is an important guarantor of law and order in the production process, ensuring not only the physical and economic availability of food for all segments of the population, but also compliance with the requirements of their safety [1].

The functions of food security are inextricably linked with the tasks of ensuring production independence, the normative regulation and implementation of which is acquiring an international character and is currently subject to the sanctions imposed against the Russian Federation, the influence of the economic crisis, rising prices, instability of the domestic currency exchange rate, etc. At the same time, an important indicator of the level of economic development of society is the characteristics of the food basket of the population, the analysis of qualitative indicators of which gives grounds to judge the level of nutrition of the population as a whole, and also forms an idea of the production of food as a fundamental type of production in general.

It should be noted that in conditions of an unfavorable epidemiological situation, the problem of food shortages is especially actualized, and is transformed into a threat to national security, exerting both a direct and an indirect impact on the health of the population. Research in this area shows that food insecurity is closely associated with a higher risk of depression, anxiety and mental disorders. Deficiency and poor nutrition contribute to an almost 3-fold increase in the number of depression and mental disorders[2].

Minimizing the impact of threats to food security and independence is associated with overcoming risks of a diverse nature, the effect of which, as practice shows, is complicated by gaps in the legal regulation system. Thus, an expert survey conducted in 2019 by the Federal Security Service showed that $69.2 \%$ of respondents noted that doing business in the Russian Federation is unsafe, and $70.7 \%$ believe that domestic laws do not guarantee the protection of business from unjustified criminal prosecution. It should be noted that entrepreneurs mentioned a business conflict ( $41 \%$ of respondents) and a personal interest of security officials or officials (36.7\%) as the reasons for initiating most of the criminal cases.

The lack of effective legal regulation of the production process, legal dementia contribute to a decrease in agricultural production and a deterioration in the nutrition of the country's population. To determine the positive direction of the processes of combating the shadow economy, mechanisms and infrastructure of control and influence of law enforcement agencies, as well as measures and tools of federal and regional management influence on economic development are required.

\section{Materials and research methods}

In the course of the application of comparative legal, statistical and sociological methods, the method of expert assessments, the study of public opinion on the perception and reproduction of normative attitudes in modern conditions was carried out, the synthesis of data on the processes of lawmaking and law enforcement in the Russian Federation.

\section{Results}

The globalization of the economy has inevitably brought food security problems into the category of the most pressing and urgent problems of all mankind. In the last two decades, the institutional foundations of the international system of food security of mankind began to form. 
In 1996, the Heads of State and Government represented by the UN adopted the Rome Declaration on World Food Security, in which states are committed to ensuring the right of everyone to have access to safe and nutritious food in accordance with the right to adequate food and the right to be free from hunger [3]

Among the main ingredients of food security in accordance with the Rome Declaration is the physical availability of sufficient quantitatively, safe and nutritious food. In 2010, Russia adopted the "Food Security Doctrine of the Russian Federation" - the only document in which specific indicators and their threshold values are legally defined, the achievement of which means ensuring the country's food security.

The Doctrine emphasizes that food security of the Russian Federation is one of the main directions of ensuring the national security of the country in the medium term, a factor of preserving its statehood and sovereignty, the most important component of demographic policy, a necessary condition for the implementation of the strategic national priority improving the quality of life of Russian citizens by guaranteeing high standards life support.

According to the Doctrine "Food security is the state of the Russian economy, in which food independence is ensured, physical and economic accessibility for the country's population of food products that meet the requirements of technical regulations, in an amount not lower than rational consumption rates necessary for an active, healthy lifestyle" is guaranteed. The Russian version of the definition links the guarantee of product quality with technical regulations, and the required level of per capita consumption with its rational norms for the main types of food.

At the turn of the century, a new noticeable threat to Russia's food security emerged the emergence of a mass of resellers operating in a wide space between agricultural producers and the country's population [4].

According to the results of the study, the respondents indicated as a threat to achieving food security: miscalculations in the management system (51\% of experts), depreciation of fixed assets (38\%), underdeveloped infrastructure $(35 \%)$, shortage of personnel in agriculture $(26 \%)$ and low the income level of a significant part of the population $(23 \%)$.

At present, the agrarian sector of the economy suffers even more from the ongoing reform of economic life, and serious miscalculations made in the course of the transformations have led Russian agriculture and animal husbandry to disaster. Despite the adoption of the Federal Law of the Russian Federation of July 9, 2002 No. 83-FL "On the financial rehabilitation of agricultural producers", about $70 \%$ of farms have overdue debts to the budgets of all levels.

It should be noted that the production of food products by domestic producers in a volume no less than the corresponding threshold values established by the Doctrine does not mean that the state of food security of the country has been achieved, since it is necessary to take into account the volume of export of these products from the country. At the same time, the physical and economic accessibility of food, as one of the characteristics of food security, can be achieved even when domestic production does not reach the established threshold values, which can be compensated for by importing necessary food products.

It should be noted that the critical threshold level of food independence, and therefore for the food security of the state, is filling the domestic market with food imports by $20 \%$ or more. Foreign food products not only occupy $28-32 \%$ of the Russian food market annually, but also demonstrate explosive growth in some areas under unfavorable conditions [5].

In the context of intensive industrial and agricultural production, high population density and the achievement of both physical and economic accessibility of food, the main focus of the problem of food security in most European countries is increasingly shifted to 
the tasks of protecting consumer rights, ensuring the ecological safety of food, and preserving the natural environment.

Achieving sustainable food security presupposes the solution of the following interrelated tasks: dynamic development of agriculture and related industries, rational regulation of export-import flows of agro-food products, reserves and resources for the needs of the agro-industrial complex, ensuring the economic and physical availability of food for all segments of the population through development market infrastructure, balanced income growth, improved living standards, convergence of conditions and quality of life in cities and rural areas.

The accession of the Russian Federation to the World Trade Organization (WTO) repeatedly actualizes the problem of the state agrarian industry in order to preserve and strengthen its competitiveness both in the domestic and global world food markets. Of course, there is a real danger that, by joining the WTO before a full-scale modernization of agricultural production, we may not implement it for a very long time, and this, in turn, will significantly complicate ensuring food security. It is possible that in order to strengthen food security in Russia, it will be necessary to develop a special state program for import substitution, similar to what has already been done in Kazakhstan, Azerbaijan and Belarus [6].

However, already now, undoubted concern is caused by the fact that if, according to the State Program for the Development of Agriculture, production from 2011 to 2020 should amount to 670 billion rubles, then the volume of state support for the industry is expected to increase only by 44 billion rubles, and almost half of these funds will come from the new land reclamation program. As a result, by the end of the State Program, support for domestic producers per ruble of gross output may be only 6.5 kopecks, which is one of the lowest in the world. Meanwhile, even today, insufficient profitability is recognized as the main factor in the slow modernization and innovative renewal of domestic agriculture (Table1).

Table 1. Profitability of agricultural organizations in the Russian Federation

\begin{tabular}{|c|c|c|c|c|c|c|}
\hline indicators & $\mathbf{2 0 0 7}$ & $\mathbf{2 0 0 8}$ & $\mathbf{2 0 0 9}$ & $\mathbf{2 0 1 0}$ & $\mathbf{2 0 1 1}$ & $\mathbf{2 0 1 8}$ \\
\hline $\begin{array}{c}\text { share of unprofitable } \\
\text { organizations, \% }\end{array}$ & 25 & 22 & 28 & 29 & 18 & 26,2 \\
\hline
\end{tabular}

However, there is currently a threat to food security in Russia, and the main problem aggravating the situation is the low level of agricultural productivity. An essential element in the agricultural sector that affects food security is industrial relations, land tenure and land use issues, the position of the producer and the worker, since this greatly affects the nature of the productive forces, their efficiency and, ultimately, the volume of food produced and efficiency of production systems (Table2).

Table2. Key performance indicators of agricultural organizations in the Russian Federation

\begin{tabular}{|c|c|c|c|c|c|c|}
\hline & $\mathbf{2 0 0 0}$ & $\mathbf{2 0 1 4}$ & $\mathbf{2 0 1 5}$ & $\mathbf{2 0 1 6}$ & $\mathbf{2 0 1 7}$ & $\mathbf{2 0 1 8}$ \\
\hline sown area, mln ha & 74,2 & 55,3 & 55,1 & 54,7 & 54,4 & 53,6 \\
\hline incl. cereals and legumes & 40,7 & 32,1 & 32,1 & 31,9 & 31,6 & 30,2 \\
\hline $\begin{array}{c}\text { entered min. fertilizers, } \\
\text { million tons }\end{array}$ & 1,4 & 1,9 & 2,0 & 2,3 & 2,5 & 2,5 \\
\hline $\begin{array}{c}\text { entered min. fertilizers per } \\
1 \text { hectare, kg of the entire } \\
\text { sown area }\end{array}$ & 19 & 40 & 42 & 49 & 55 & 56 \\
\hline $\begin{array}{c}\text { use of min. fertilizers: } \\
\text { import. thousand tons }\end{array}$ & 126,9 & 55,2 & 69,6 & 88,4 & 212,7 & 218,1 \\
\hline
\end{tabular}




\begin{tabular}{|c|c|c|c|c|c|c|}
\hline $\begin{array}{c}\text { head of cattle, million } \\
\text { heads }\end{array}$ & 10,5 & 8,3 & 7,9 & 7,6 & 7,5 & 7,4 \\
\hline incl. cows & 6 & 3,8 & 3,6 & 3,4 & 3,4 & 3,4 \\
\hline
\end{tabular}

Chronic underfunding of measures for sustainable development of rural areas, the basis of social development of the countryside, is also of great concern. Since 2009, it has decreased by 3 times in comparison with the previously provided size. As a result, destructive processes continue in rural areas: for example, from 2001 to 2010 , the rural population decreased by 1.7 million people, and the Russian village lost 2.2 thousand settlements. Rural ecology and the creation of a harmonious living environment is one of the main functions of the agri-food sector of any country. Performing this function requires significant expenditures, which are feasible for advanced economies. On the contrary, troubled states cannot allocate the necessary resources for the development of rural areas, which leads to an outflow of the rural population to cities, to depopulation of villages. Unfortunately, this is especially true for many regions of Russia [7]

Scientists note that while maintaining the current development trends, the exponential nature of the growth in demand for arable land leads at a certain point to their sharp and critical shortage, i.e. a crisis can come suddenly and there will be little time for a response [9]. Intensive farming often leads to a vicious circle of depletion of soil fertility and a decrease in crop yields [10].

Agri-food sector is a complex socio-ecological-economic system, which is designed to: provide food production to meet the needs of the population in food, preserving and supporting its life and reproduction; to promote employment and socio-cultural development of the rural population; use and restore soil fertility and ecological balance in rural areas [11].

One of the latest projects of federal importance is the creation of a Situation Center for Monitoring Food Security. However, today only an information system has been created in the field of ensuring food security.

In recent years, the problem of food safety for consumers has become especially acute in Russia, which is associated with an increase in the supply of low-quality, falsified and hazardous products to the food market. According to the estimates of the National Fund for the Protection of Consumer Rights, in small wholesale and food markets, up to $85 \%$ of food products are falsified to one degree or another.

In Russia, state control is exercised in the field of ensuring the quality and safety of agricultural products, raw materials and food. So, in the Rostov region, one of the components of the monitoring work is laboratory testing of food raw materials and food products, carried out by the Center for Hygiene and Epidemiology on behalf of the Office of Rospotrebnadzor in the Rostov Region. Studies for physical and chemical indicators, including indicators of the authenticity of the composition, are an integral part of ensuring the quality and safety of food raw materials and food products. In the structure of inappropriate samples in terms of physical and chemical indicators, the leading ranking places are occupied by fish and non-fish objects of fishing, milk and dairy products, meat and meat products, canned food, confectionery [12].

For a number of years, salmonellosis pathogens have been found in poultry and poultry products, fish and fish products, listeria - in meat and meat products, toxin and botulism - in homemade products (such as canned vegetables, dried fish). In recent years, the importance of finished products (culinary products, confectionery products) as a factor in the transmission of pathogenic microorganisms has increased.

The discrepancies in quality and safety indicators identified in food products most likely indicate the absence of systematic actions on the part of participants in the production and circulation of food products to eliminate risk factors. In the current economic conditions, 
the introduction of quality management systems, including procedures based on the principles of HACCP, into activities for the production and circulation of food products (primarily high risk, including meat, dairy, culinary products) (Hazard Analysis and Critical Control Points), in accordance with the requirements of TR CU 021/2011 "On food safety", along with maintaining traditional control methods, will give confidence that safety is effectively ensured. The cheapness of food, which is produced in an industrial way, in which hormones and various additives are used, entail an increase in the number of food anomalies and poisonings.

This situation can be characterized as a very significant threat to the health of the nation. Most countries have already created an extensive system of legal support for national food security. In 1955, the German Agriculture Act was passed in Germany. "The law notes that the state must fully consider the problem of supplying the population with food as a strategic one, form food 13 funds, and make food supplies independent from third countries." Based on the Law on Ensuring the Stability of Agricultural Production, the French Ministry of Agriculture develops a national agricultural policy and is responsible for its implementation. The competitiveness of agricultural producers is supported by the state, the state also regulates the domestic market for agricultural products, ensures that food imports do not harm domestic agricultural production in any way, and that the prices of imported goods are not lower than world prices and the prices of the domestic market. In 1947, Sweden adopted the Law "On the rationalization of agriculture", it is aimed primarily at supporting the competitiveness of its agricultural producers and at limiting the import of food raw materials through quotas and duties. In the process of stimulating agricultural production, the state proceeds from the provision that farmers' incomes should not be lower than the wages of an averagely skilled worker who works in industry [17].

\section{Conclusion}

In 2002, Regulation 178/2002 of the European Parliament and of the Council of Europe was adopted, defining measures to ensure food safety. Specially developed technical regulations for the products of the food industry should contain only the minimum necessary mandatory requirements, and national standards should contain extended ones. In this regard, in Russia, it is necessary to conduct a comprehensive analysis of the existing models of technical regulation in the EU countries and make a decision on the appropriateness of using European principles.

The current state of food security can be significantly influenced by:

- high concentration of agricultural production in individual holdings, which in the event of bankruptcy can cause serious damage to the industrial safety of the region;

- control over the largest agro-industrial holdings of Russia by foreign individuals and legal entities.

At the EU level, there are three main objectives of food law:

- health protection (only safe food products are to be sold);

- protecting consumers from fraud;

- proper public awareness.

All relevant legal provisions (in particular, the German food law includes more than 200 regulations and laws) are subject to the achievement of these objectives.

In addition, the European Union has the so-called "seven basic principles of food safety":

1. the principle of interaction between all links of the food chain;

2. entrepreneur responsibility principle;

3. traceability principle;

4. principle of independent scientific risk assessment; 
5. principle of separation of powers between the areas of risk assessment and risk management;

6. prevention principle;

7. principle of transparent risk communication [12].

The European approach is largely similar to the doctrine of legitimate expectations formed in English law and consists in ensuring, within the framework of a specific legal order, a model of legal relations in which their participants could build their behavior based on the established practice of public authorities on the basis of general legal principles of legal certainty in relation to European approach and justice [14].

Moreover, the connectedness of the doctrine of legitimate expectations and the principle of legal certainty lies in the need to create legal conditions aimed at providing individuals with the opportunity to organize their business activities on the basis of assurances received from a public authority or the established practice of such a body [15]. In addition, it is also necessary to pay attention to the fact that due to the lack of special knowledge of the majority of citizens on the relevant issue, the decision taken on this issue in most cases is not at all mediated by an analysis of the risks that can be realized as a result of its adoption [16]

Thus, in Russia, the problem of food self-sufficiency has an important socio-economic support. It is known that the expansion of imported goods occurs not so much through the development of free market niches, but as a result of direct displacement of similar Russian goods from the Russian market. In this context, food self-sufficiency should be seen as a necessary condition for maintaining the income of the rural population and counteracting the outflow of the latter to cities and preventing rural degradation.

The deterioration in nutrition is caused not only by a decrease in the production of basic food products, the curtailment of the food industry, but also by a fall in the purchasing power of the population, and an increase in the number of people living below the poverty line.

Agricultural production and food markets, not being self-regulating in modern conditions, cannot function successfully without constant government intervention and support. The most important elements of the state regulation system in the agricultural sector in Russia should be:

- maintaining the overall level of profitability in the industry by supporting the industry and stimulating the solvency of demand;

- antitrust regulation;

- pursuing a policy of reasonable protectionism;

- providing domestic producers with conditions for normal competition with the foreign market.

In order to increase the efficiency of the implementation of national priorities, minimize the impact on the state of food security of internal and external threats, it is proposed to create a codified branch of food law with the definition of the following goals of legislation: the competitiveness of domestic agricultural producers, ensuring the environmental safety of food, the priority of consumer rights, and the preservation of the natural environment.

\section{References}

1. E.N. Krylatykh, V.Z. Mazloyeva, National Economy: Ensuring Food Security in the Context of Integration and Globalization 194 (2016)

2. D.J. Arenas, A. Thomas, Ji Ci Wang, H.M. DeLisser, A Systematic Review and Metaanalysis of Depression, Anxiety, and Sleep Disorders in US Adults with Food Insecurity. Journal of General Internal Medicine (2019) 
3. C.P. Timmer, Food Security and Scarcity: Why ending hunger is so hard. University of Pennsylvania Press (2015)

4. S.N. Baburin, M.I. Dzliyev, A.D. Ursul, National Security Strategy: Theoretical and Methodological Aspects 273 (2012)

5. V.Sh. Urazgaliev, Economic security: textbook and workshop for universities 157 (2018)

6. E. Shapero, Greenbelts Feed Cities: Long-Term Food Security Start with Protected Farmland. Alternatives Journal 43(2) (2017)

7. D. Zilberman, S. Kaplan, E. Kim, S. Sexton, Barrows, Geoffrey. Biotechnology and Food Security. Journal of International Affairs 67(2) (2014)

8. J. Bremer, State capitalism comes of age: The end of free market? Foreign affairs 4055 (2009)

9. C. Christensen, Progress and Challenges in Global Food Security. Amber Waves (2018)

10. F.N. Finley, The Anthropocene and the Frameworkfor K-12 Science Education// Future Earth-Advancing Civic Understanding of the Anthropocene. Hoboken, NJ: John Wiley \& Sons, Inc. 9-17 (2014)

11. V.I. Nazarenko, Food security (in the world and in Russia) 204 (2011)

12. P. Leyland, G. Anthony, Textbook on Administrative Law. Oxford Universitu Press 44-45 (2013)

13. L.A. Kormishkina, N.N. Semenova, Monitoring of Food Security in the Russian Federation: Methodology and Assessment. European Research Studies 19(3) SI A (2016)

14. V.V. Eremyan, E.T. Eshinimaeva-Shagdarova, International Aspeckts of Brexit: Britains Overseas Territories u Gibraltar. Journal of Fundamental and Applied Sciences 10 (2018)

15. International Aspeckts of Brexit: Britains Overseas Territories u Gibraltar. Journal of Fundamental and Applied Sciences 10 (2018)

16. J.L. Pomeranz, Food Law for Public Health. Oxford University Press (2016) 